\title{
Produtividade e composição estrutural de aveia e azevém submetidos a épocas de corte e adubação nitrogenada
}

\author{
Luís César Cassol', Jonatas Thiago Piva², André Brugnara Soares ${ }^{1}$, Alceu Luiz Assmann ${ }^{3}$
}

\begin{abstract}
RESUMO
A atividade leiteira é fundamental para a pequena propriedade do sudoeste do Paraná. Este estudo teve como objetivo avaliar o efeito de épocas de corte de pastagem de aveia e azevém, com e sem adubação nitrogenada, sobre a produção de matéria seca e a qualidade da pastagem. O experimento foi conduzido em Pato Branco, PR, num delineamento de blocos ao acaso, com parcelas subdivididas e quatro repetições. Nas parcelas, fez-se uso de adubação nitrogenada de cobertura ( 0 e $100 \mathrm{Kg}_{\text {de }} \mathrm{N} \mathrm{ha}^{-1}$ ), na forma de ureia, e, nas subparcelas, foram avaliadas três épocas de corte de pastagem de aveia e azevém (30, 45 e 60 dias após a emergência). A aplicação de nitrogênio proporcionou um acúmulo de massa de $1133 \mathrm{Kg}$ de MS ha-1 aos 45 dias após a emergência, próximo daquele considerado ideal para início de pastejo. O primeiro corte nessa época, combinado com o uso de nitrogênio, também favoreceu a capacidade de rebrota da pastagem, pois 30 dias após esse corte, o acúmulo de massa alcançou $2398 \mathrm{Kg}_{\mathrm{g}} \mathrm{MS} \mathrm{ha}^{-1}$. A adubação nitrogenada aumentou a quantidade de folhas de aveia na pastagem, fato que contribuiu para que o teor de proteína bruta fosse de $27 \%$, indicando alta qualidade do material.
\end{abstract}

Palavras-chave: Potencial de produção, pastagem de inverno, proteína bruta.

\section{ABSTRACT}

\section{Yield and structural composition of oat and ryegrass subjected to different periods of cutting and nitrogen fertilization}

Dairy farming represents an important activity to small farmers, in south-west of Parana State, Brazil. The objective of this study was to evaluate the effect of the harvest period of oat and rye grass pastures, with and without nitrogen fertilization, on dry matter and pasture quality in order to determine the best time to start grazing. The experiment was carried out in Pato Branco, PR, in a randomized block design in split plot arrangement, with four repetitions. The main plot consisted of nitrogen fertilization levels ( 0 and $100 \mathrm{~kg} \mathrm{ha}^{-1}$ of $\left.\mathrm{N}\right)$, in the form of urea. The sub plots consisted of three cutting times of oat and rye grass pasture (30,45 and 60 days after plants cropping up). The nitrogen applied provided dry mass accumulation of $1133 \mathrm{~kg} \mathrm{DM} \mathrm{ha}^{-1} 45$ days after emergence, close to the amount considered adequate to start grazing. The first cutting, at this time, in association with the use of nitrogen also influenced the pasture regrowth capacity, which was indicated by the dry mass accumulation of $2398 \mathrm{~kg}$ of DM ha-1 obtained $_{30}$ days after this cutting. Nitrogen fertilization increased the number of oat leaves, which contributed to the high level of crude protein content (27\%), showing the high quality of the material.

Key words: Potential production, winter pasture, crude protein.

Recebido para publicação em 22/03/2010 e aprovado em 12/07/2011

${ }^{1}$ Engenheiro-Agrônomo, Doutor. Universidade Tecnológica Federal do Paraná (UTFPR), Via do Conhecimento km 01, 85501-970, Pato Branco, Paraná, Brasil. *cassol@utfpr.edu.br (*autor para correspondência), soares@utfpr.edu.br

${ }^{2}$ Engenheiro-Agrônomo, Mestre. Doutorando do PPGPV-Agronomia, Universidade Federal do Paraná (UFPR), Rua dos Funcionários, 1540, 80035-050, Curitiba, Paraná, Brasil. jonatastpiva@yahoo.com.br

${ }^{3}$ Engenheiro-Agrônomo, Doutor. Instituto Agronômico do Paraná (IAPAR), BR 158, km 497, C. Postal 510, 85505-970, Pato Branco, Paraná, Brasil. assmann@iapar.br 


\section{INTRODUÇÃO}

A cadeia produtiva do leite, no Estado do Paraná, é formada por $84 \%$ de pequenos produtores, que apresentam índices de produtividade inferiores a 2.000 litros/vaca/ ano, o que significa uma média diária abaixo de 5,5 litros/ vaca. Por outro lado, apenas $4 \%$ produzem 4.000 ou mais litros/vaca/ano (Hofer \& Shikida, 2000).

O sudoeste do Estado possui a segunda maior bacia produtora de leite do Paraná, com mais de 500 milhões de litros/ano, distribuídos em cerca de 15 mil propriedades, as quais são exploradas, essencialmente, por agricultores familiares. Esta atividade tem sido eficiente em sustentar as famílias no campo, especialmente pela geração de uma renda mensal.

A maior parte da produção de leite ocorre sobre pastagens anuais de inverno e perenes de verão. Entre as forrageiras de inverno, os grandes destaques são: a aveia preta (Avena strigosa), pela rusticidade, baixa exigência em fertilidade e uso como cobertura de solo (Floss, 2001),e o azevém (Lolium multiflorum), pela facilidade de ressemeadura natural, resistência a doenças, elevado potencial de produção de sementes e pela versatilidade em consorciações.

Além da cobertura vegetal, essas espécies podem ser utilizadas para pastejo, pela elevada qualidade nutricional, desde que manejadas corretamente. Esse manejo consiste na tomada de decisões técnicas capazes de manter o equilíbrio entre dois fatores conflitantes de produção: a exigência nutricional do animal sob pastejo e a exigência fisiológica da planta forrageira para alcançar e manter elevada produtividade (Corsi \& Nascimento Junior, 1994). Como recomendação prática de manejo, sugere-se que o início do pastejo ocorra quando a massa de forragem atin-

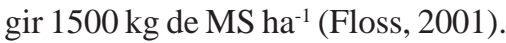

A entrada precoce dos animais prejudica o pasto, pelo pisoteio em solo descoberto ou com pouca massa, contribuindo para um possível aumento da densidade superficial do solo (Cassol, 2003). O arranquio de plantas pelo pastejo antecipado pode diminuir a densidade de perfilhos e a área foliar do pasto, comprometendo as produções da forragem e do animal. Se após a entrada dos animais, a intensidade de pastejo for muito elevada, condicionando uma massa de forragem baixa, a altura do corte pelo pastejo ocorrerá abaixo do meristema apical em grande parte dos perfilhos, prejudicando a área foliar do pasto, a interceptação da radiação, a fotossíntese líquida e a taxa de produção de folhas (Richards, 1993).

A adubação nitrogenada no perfilhamento dos pastos anuais de inverno pode reduzir o vazio forrageiro e antecipar o início do pastejo, pois este elemento é fundamental ao crescimento de plantas, especialmente das Poaceas (Lupatini et al., 1998). No entanto, o usual entre os produ- tores da região é aproveitar o efeito residual da adubação nitrogenada fornecida para a cultura de verão e não adubar as pastagens de inverno. A ausência de nitrogênio, associada ao corte prematuro dos pastos pelos bovinos (cerca de 30 dias após a emergência), pode comprometer o crescimento da aveia e do azevém.

Em função disso, o objetivo deste trabalho foi avaliar o efeito de diferentes épocas de corte de pastos de aveia, consorciada com azevém, submetidos ou não à adubação nitrogenada, sobre a produção de matéria seca, teor de proteína bruta e composição estrutural do pasto.

\section{MATERIAL E MÉTODOS}

O experimento foi conduzido em Área Experimental da Universidade Tecnológica Federal do Paraná (UTFPR), em Pato Branco, em altitude de $750 \mathrm{~m}$, latitude de $26^{\circ} 17^{\prime} \mathrm{S}$ e longitude de $52^{\circ} 41^{\prime} \mathrm{W}$. O clima da área é o Cfa, conforme classificação de Köppen, e o solo classificado como Latossolo Vermelho distrófico, de acordo com o Sistema Brasileiro de Classificação de Solos (Embrapa, 1999), apresentando os seguintes atributos químicos, na camada de 0-20 cm, antes do início do experimento: matéria orgânica

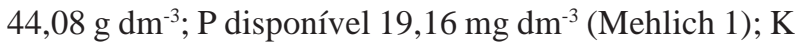

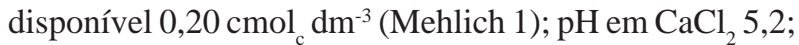
$\mathrm{Ca}, \mathrm{Mg}$ e Al trocáveis $\left(\mathrm{KCl} 1 \mathrm{~mol} \mathrm{~L}^{-1}\right), 5,18,3,20$ e $0,0 \mathrm{cmol}$ $\mathrm{dm}^{-3}$, respectivamente.

O delineamento experimental foi o de blocos ao acaso, com parcelas subdivididas e quatro repetições. Nas parcelas principais ( $6 \times 18 \mathrm{~m}$ ), foram aplicadas duas doses de nitrogênio ( 0 e $100 \mathrm{Kg}_{\text {de }} \mathrm{N} \mathrm{ha}^{-1}$ ), em cobertura, divididas em três aplicações (imediatamente após a emergência, 30 e 60 dias após a primeira aplicação), usando-se ureia como fonte. Nas subparcelas ( 6 × $6 \mathrm{~m}$ ), foram avaliadas três épocas de corte do pasto, aos 30, 45 e 60 dias após emergência (DAE).

O pasto foi formado por um consórcio de aveia e azevém, implantado no dia 02 de junho de 2005, numa densidade de $150 \mathrm{~kg}$ de sementes de aveia ha ${ }^{-1}$ e $30 \mathrm{~kg}$ de sementes de azevém ha ${ }^{-1}$, não sendo efetuado nenhum tipo de adubação. Após a semeadura, que foi feita a lanço, procedeu-se uma gradagem leve para a incorporação das sementes ao solo.

Em cada época de corte do pasto, foi retirada uma amostra de $0,25 \mathrm{~m}^{2}$, cortada rente ao solo, para determinar a produção de matéria seca (MS), após secagem em estufa, a $60^{\circ} \mathrm{C}$. Nesse mesmo material, procedeu-se à quantificação dos componentes estruturais da planta, por meio da separação manual de lâmina foliar e de colmo (colmo e bainha) de aveia e de lâmina foliar e de colmo de azevém.

Após essa amostragem, toda a subparcela foi cortada a cinco centímetros de altura do solo. A rebrota da planta foi novamente quantificada por meio da produção de MS, 
realizando-se um segundo corte da forragem, sempre 30 dias após o corte anterior. Então, os tratamentos de época de corte ficaram assim constituídos: $30+30,45+30$ e $60+$ 30 , onde o primeiro número significa DAE e o segundo número significa dias após o corte anterior.

Além da MS e da composição estrutural das espécies, no primeiro corte também se determinou o teor de proteína bruta em função dos tratamentos aplicados, de acordo com metodologia descrita em Tedesco et al. (1995).

Os resultados das avaliações foram submetidos à análise da variância, para se verificarem possíveis diferenças entre os tratamentos e a existência de interação entre nível de nitrogênio e regime de cortes, para cada variável dependente. Para comparação entre as médias dos tratamentos, foi utilizado o teste de Tukey a $5 \%$ de significância.

\section{RESULTADOS E DISCUSSÃO}

Os resultados de produção de MS da parte aérea, no primeiro corte, indicam que ocorreu interação $(\mathrm{p}=0,00131)$ entre a aplicação de nitrogênio e as épocas de corte do pasto. Em qualquer época de corte, a maior produção de MS foi obtida com aplicação de nitrogênio, sendo que, aos 30 DAE, somente $1 / 3$ da dose de $\mathrm{N}$ foi suficiente para apresentar diferença em relação ao tratamento sem N. Da mesma forma, independentemente do uso de nitrogênio, o retardamento da data de corte promoveu maior produção de forragem (Figura 1).

O nitrogênio é um dos nutrientes essenciais ao crescimento das plantas. A produção da forragem aumenta com o uso de adubação nitrogenada, dentro de certos limites e, consequentemente, aumenta a capacidade de suporte

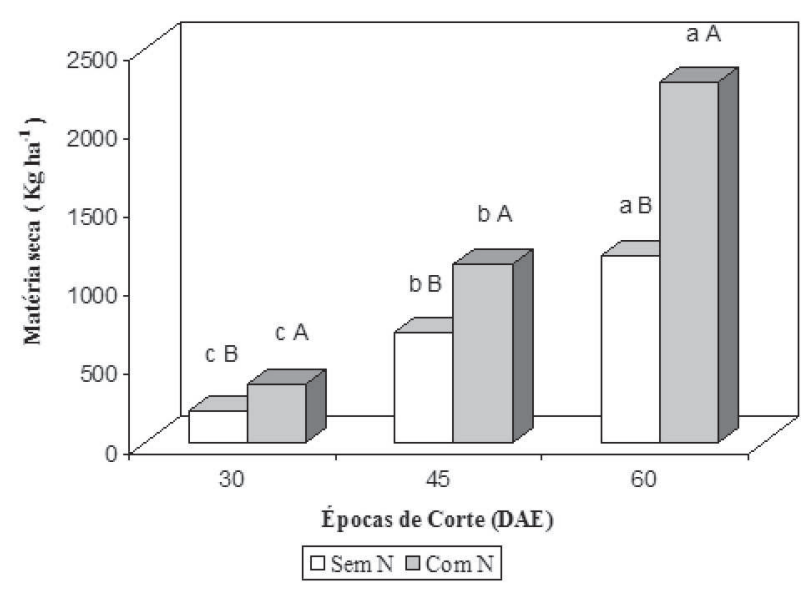

Figura 1. Produção de matéria seca do primeiro corte de pastos de aveia e azevém, em função de doses de nitrogênio e épocas de corte. Médias seguidas de letras distintas, maiúsculas, comparando doses de $\mathrm{N}$ dentro de cada época de corte, e minúsculas, comparando épocas de corte dentro do fator $\mathrm{N}$, diferem entre si pelo Teste de Tukey a $5 \%$. Sem N $=$ sem nitrogênio; Com $\mathrm{N}=$ com $100 \mathrm{Kg}$ de $\mathrm{N} \mathrm{ha}^{-1}$. da pastagem. Ben et al. (1998), trabalhando com doses de $\mathrm{N}$ em cobertura, na aveia, obtiveram resposta de produção de MS até a dose de $160 \mathrm{Kg}_{\text {de N ha-1 }}{ }^{-1}$, aplicados 27 dias após a emergência. Aplicando doses crescentes de N, Moreira et al. (2001), em dois cortes de aveia preta, obtiveram produção total de MS de 3283, 4691, 4993 e $5471 \mathrm{Kg} \mathrm{ha}^{-1}$, para doses de 0, 50, 100 e $200 \mathrm{Kg}_{\mathrm{de}} \mathrm{N} \mathrm{ha}^{-1}$, respectivamente . Lang (2004) obteve aumento na produção de MS de aveia e azevém com a dose de $150 \mathrm{~kg}$ de $\mathrm{N}$ $\mathrm{ha}^{-1}$, além de uma melhoria na qualidade dessa forrageira, aumentando as folhas em relação ao colmo e diminuindo a relação $\mathrm{C} / \mathrm{N}$.

No entanto, neste trabalho, mesmo com aplicação de nitrogênio, aos 30 dias após a emergência, o acúmulo de matéria seca ainda foi pequeno, atingindo, aproximadamente, $500 \mathrm{~kg} \mathrm{MS} \mathrm{ha}^{-1}$. Aos 45 dias após a emergência, houve um acúmulo de massa de $1133 \mathrm{~kg} \mathrm{MS} \mathrm{ha}^{-1}$, quando se utilizou fertilização nitrogenada, e, aos 60 dias após a emergência, esse acúmulo foi de $2285 \mathrm{~kg} \mathrm{MS} \mathrm{ha}^{-1}$ (Figura 1). Floss (2001), recomenda que os animais devam entrar na pastagem quando houver uma disponibilidade de aproximadamente $1500 \mathrm{~kg} \mathrm{ha}^{-1}$. Assim, os resultados obtidos neste trabalho indicam que é possível iniciar-se o pastejo de aveia e azevém, aproximadamente entre 45 e 60 dias após a emergência das espécies, desde que ocorra suplementação nitrogenada, o que normalmente não é realizado pelos produtores da região.

Definir o momento certo de entrada dos animais em pastagem de aveia e azevém é extremamente importante. Para isso, é necessário conciliar quantidade e qualidade da massa de forragem produzida. Primavesi et al. (2001), trabalhando com os cultivares de aveia São Carlos, UPF 3 e IAPAR 61, em diferentes épocas de corte e rebrota, com a aplicação de $180 \mathrm{~kg}$ de $\mathrm{N} \mathrm{ha}^{-1}$, concluíram que o primeiro corte deve ser feito na fase de elongação de colmo (38-45 DAE), pois foi o momento em que os cultivares apresentaram alto valor nutritivo e produção de MS. Rodrigues \& Godoy (2000), avaliando a produção de matéria seca e proteína bruta da aveia com aplicação de 80 $\mathrm{Kg}$ de $\mathrm{N} \mathrm{ha}^{-1}$, encontraram valores de MS aos 30 DAE de $1700 \mathrm{Kg}$ de $\mathrm{MS} \mathrm{ha}^{-1}$, chegando a $4825 \mathrm{Kg}_{\mathrm{ge} \mathrm{MS} \mathrm{ha}}{ }^{-1}$ aos 100 DAE, havendo relação inversa quanto ao teor de PB, diminuindo de 24 para $13 \%$ com esse aumento de MS.

Quando não se utilizou adubação nitrogenada, foram necessários mais 15 dias para acumular uma quantidade de MS semelhante à obtida quando do uso do N, ou seja, a produção de MS aos 45 DAE e com aplicação de $100 \mathrm{Kg}$ de $\mathrm{N} \mathrm{ha}^{-1}$ foi semelhante àquela conseguida aos $60 \mathrm{DAE} \mathrm{e}$ sem N. Nesse primeiro corte, a maior produção de MS, $2.285 \mathrm{Kg}_{\text {de }} \mathrm{MS} \mathrm{ha}^{-1}$, foi obtida aos $60 \mathrm{DAE}$ das espécies e fazendo-se uso de nitrogênio (Figura 1). Matzembacher (2001), avaliando a produção de MS de diferentes cultivares de aveia, conseguiu realizar quatro cortes, aplicando 
$50 \mathrm{Kg} \mathrm{N} \mathrm{ha}^{-1}$ a cada corte e obtendo média de produção de MS de $3.621 \mathrm{Kg} \mathrm{ha}^{-1}$.

Para solos com teores médios de matéria orgânica, como os encontrados neste trabalho, a CQFS RS/SC (2004) recomenda, para gramíneas anuais de estação fria, a aplicação de 40 a $100 \mathrm{Kg}$ de $\mathrm{N} \mathrm{ha}^{-1}$, para expectativa de rendimento de até $5000 \mathrm{Kg} \mathrm{ha}^{-1}$, avaliado na fase de pleno florescimento. A dose de $100 \mathrm{Kg}_{\mathrm{de}} \mathrm{N} \mathrm{ha}^{-1}$, para pastos de aveia e azevém, utilizada neste trabalho, proporcionou, já aos 60 DAE, uma produção de massa de $2285 \mathrm{~kg} \mathrm{ha}^{-1}$, superior àquela encontrada por Cassol (2003) que, nesse mesmo período, obteve uma produção de $1700 \mathrm{~kg} \mathrm{MS} \mathrm{ha}^{-1}$ de aveia e azevém. É importante salientar que aos $60 \mathrm{DAE}$ a aveia encontra-se em estádio juvenil e que, no pleno florescimento, sua produção tende a alcançar os mesmos $5000 \mathrm{~kg} \mathrm{MS} \mathrm{ha}^{-1}$ preconizados pela CQFS RS/SC (2004), indicando que $100 \mathrm{~kg} \mathrm{~N} \mathrm{ha}^{-1}$ seriam adequados para essa pastagem.

Um segundo corte da parte aérea da pastagem foi realizado 30 dias após o corte anterior, nos tratamentos de época de corte. Os resultados demonstram novamente o efeito da adubação nitrogenada sobre a produção de MS (Figura 2). Entretanto, percebe-se que, no tratamento $60+$ 30 (60 DAE + 30 dias após o primeiro corte) a produção foi inferior à obtida com o tratamento $30+30$ (30 DAE + 30 dias após o primeiro corte), quando se fez uso de nitrogênio (Figura 2).

No tratamento $60+30$, o pasto estava com aproximadamente 100 dias desde a semeadura. É possível que, nesse caso, a contribuição da aveia para a produção de MS esteja em declínio, em função do seu ciclo mais curto. Já no tratamento $30+30$, tanto aveia como azevém encontravam-se em pleno desenvolvimento vegetativo, favorecendo a maior produção de massa seca. Outra hipótese para

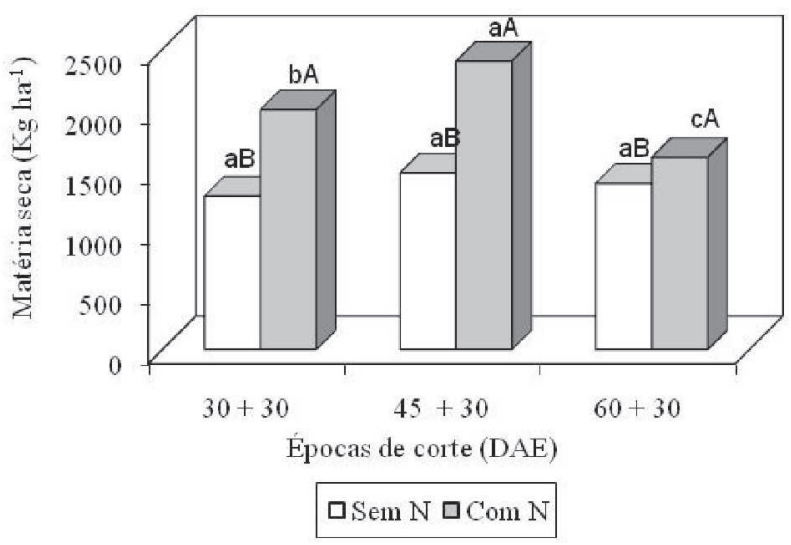

Figura 2. Produção de matéria seca do segundo corte (30 dias após o primeiro) de pastos de aveia e azevém, em função de doses de nitrogênio e épocas de corte. Médias seguidas de letras distintas, maiúsculas, comparando doses de $\mathrm{N}$ dentro de cada época de corte, e minúsculas, comparando épocas de corte dentro do fator N, diferem entre si pelo Teste de Tukey a 5\%. Sem N = sem nitrogênio; Com $\mathrm{N}=$ com $100 \mathrm{Kg}$ de $\mathrm{N} \mathrm{ha}^{-1}$. explicar a menor produção do tratamento $60+30$, no segundo corte, é que maior percentagem de perfilhos teve seu meristema apical removido no primeiro corte, pois as plantas desse tratamento tiveram 60 dias para receber o primeiro corte. A maior produção do primeiro corte vem em detrimento da produção do segundo, uma vez que, quando os perfilhos têm seu meristema apical removido, a rebrotação ocorre pela diferenciação das gemas axilares e novo perfilhamento, processo, porém, mais lento, quando comparado com aquele em que o meristema apical não interrompe o processo de produção de folhas.

Os melhores resultados, no segundo corte, foram obtidos com a combinação de primeiro corte aos 45 DAE, mais 30 dias de intervalo, acrescidos de $100 \mathrm{Kg}_{\text {de }} \mathrm{N} \mathrm{ha}^{-1}$ (Figura 2). Neste caso, foram obtidos cerca de $2.400 \mathrm{Kg}$ de $\mathrm{MS} \mathrm{ha}^{-1}$, quantidade que, somada à do primeiro corte, fornece uma produção acumulada de $3.500 \mathrm{Kg}$ de $\mathrm{MS}_{\text {ha }}{ }^{-1}$ com apenas 85 dias de ciclo desde a semeadura.

Em relação à composição estrutural do dossel, realizada apenas no primeiro corte, a aplicação de nitrogênio aumentou sensivelmente a quantidade de folhas de aveia, em todas as épocas de corte (Figura 3). O nitrogênio proporciona à planta maior produção de biomassa, maior produção de perfilhos por planta e melhora a qualidade da pastagem, por proporcionar um aumento na percentagem de folhas, que é um material de melhor digestibilidade, menos fibroso e mais palatável para os animais, em relação ao colmo.

A redução na contribuição de folhas de aveia, com o avanço do estádio de crescimento, também foi observada por Reis et al. (1992). Por sua vez, Cassol (2003), trabalhando com pastejo de aveia e azevém, observou que, com cerca de 100 dias de ciclo, aproximadamente $60 \%$ da pastagem era composta pela aveia. Deve-se considerar que, no trabalho de Cassol (2003), o azevém foi obtido por ressemeadura natural, fato que pode ter contribuído para que essa espécie não competisse em igualdade de condições com a aveia, conforme citado pelo autor.

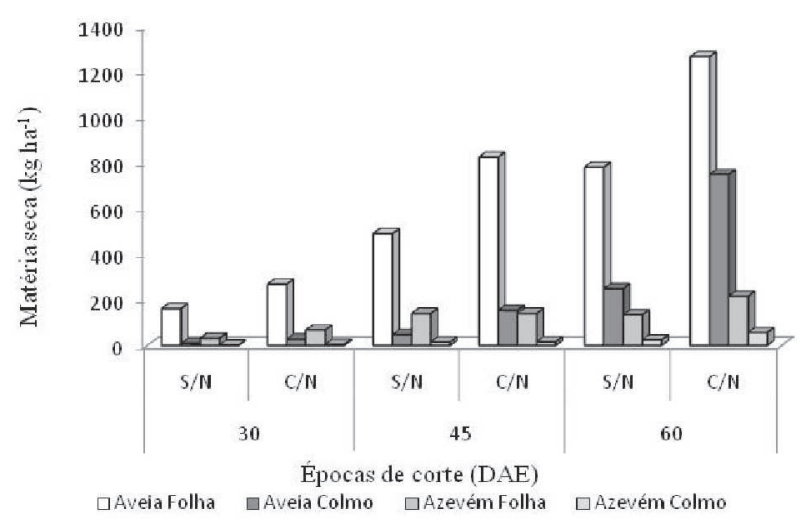

Figura 3. Composição estrutural de pastos de aveia e azevém, em função de doses de nitrogênio e épocas de corte. $\mathrm{S} / \mathrm{N}=$ sem nitrogênio; $\mathrm{C} / \mathrm{N}=$ com $100 \mathrm{Kg}$ de $\mathrm{N} \mathrm{ha}^{-1}$.

Rev. Ceres, Viçosa, v. 58, n.4, p. 438-443, jul/ago, 2011 
Um aspecto a ser considerado, neste trabalho, é a época de semeadura das espécies, que ocorreu no mês de junho, considerado tardio para produção de forragem de aveia no sul do Brasil (clima Cfa), o que pode ter contribuído para a redução da contribuição das folhas de aveia ao longo do tempo. Ferolla et al. (2007), trabalhando com aveia preta em diferentes épocas de semeadura (abril, maio e junho), numa condição de clima Aw, quente e úmido, com precipitação pluviométrica de 1.023 mm, observaram maior relação lâmina foliar/colmo, quando esta foi semeada no mês de junho. A maior contribuição de folhas em relação ao colmo no período vegetativo, também foi observada em trabalho realizado com pastos de aveia e azevém, com diferentes alturas de manejo (Aquinaga et al., 2008). Rocha et al. (2004), avaliando a composição botânica da pastagem de aveia e azevém, observaram a predominância de lâminas de aveia no período inicial de desenvolvimento da cultura em relação ao azevém, graças à disposição e arquitetura das folhas de aveia, que suprimem o azevém pela competição de luz sob o dossel.

O azevém também teve incremento de produção com a adução nitrogenada, menos aos $45 \mathrm{DAE}$, quando não se verificou diferença significativa (Figura 3). No entanto sua média de produção foi menor, quando comparada com a da aveia. Isso se deve ao fato de o azevém apresentar um ciclo mais tardio, ocasionando maior produção nos cortes seguintes.

A produção de folhas de aveia, com uso de nitrogênio, foi de $820 \mathrm{Kg} \mathrm{ha}^{-1}$, aos $45 \mathrm{DAE}$, ligeiramente superior àquela obtida aos $60 \mathrm{DAE}$, sem uso de nitrogênio, que foi de $800 \mathrm{Kg} \mathrm{ha}^{-1}$. Esse resultado de maior produção de folhas de aveia com o uso de nitrogênio tem um impacto extremamente importante nos sistemas de produção, pois confirma a possibilidade de antecipação da entrada dos animais na pastagem, diminuindo efetivamente o vazio forrageiro e o custo de produção de leite, no outono, nessa região.

Não houve interação significativa $(\mathrm{P}>0,05)$ entre nível de $\mathrm{N}$ e épocas de corte, em relação ao teor de $\mathrm{PB}$ das plantas, sendo este influenciado apenas pelo nitrogênio utilizado (Figura 4). O teor de PB aumentou de 22 para $27 \%$, com o uso de 0 e de $100 \mathrm{Kg}$ de $\mathrm{N} \mathrm{ha}^{-1}$, respectivamente. Resultados semelhantes foram encontrados por Soares \& Restle (2002), em pastos de triticale e azevém, onde o teor de PB aumentou de 24 para $27 \%$, com a dose de $150 \mathrm{Kg}$ de $\mathrm{N} \mathrm{ha}^{-1}$.

Esse resultado era esperado, pois outros trabalhos (Alvim \& Moojen, 1984) com emprego de aveia e azevém também encontraram resultados semelhantes, embora com variações nos teores. Corroborando os dados do presente trabalho, Lupatini et al. (1998) encontraram valores de PB de 19,7, 24,9 e 32,4\%, no início do período de pastejo (metade de julho), e os menores, 8,6, 10,9 e 16,6\%, no final de outubro, com 0,150 e $300 \mathrm{~kg} \mathrm{ha}^{-1}$ de N, respectivamente. Da mesma forma, Moreira et al. (2001) encontraram aumento nos teores de proteína bruta e redução na fibra em detergente ácido, à medida que se aumentaram os níveis de nitrogênio.

Entretanto, mesmo sem adubação nitrogenada, o nível de proteína bruta da pastagem pode ser considerado alto, além da necessidade dos animais em pastejo. Animais em terminação, por exemplo, necessitam 12\% de PB e, neste experimento, mesmo sem o uso de $\mathrm{N}$, o nível foi de $22 \%$. Esse resultado demonstra que o uso de $\mathrm{N}$ em pastagem de aveia e azevém não deve ser realizado com vistas a aumentar o ganho individual dos animais, mas, sim, para proporcionar condições adequadas para antecipação do início de pastejo, ou aumentar a produção animal e de forragem.

Geralmente, o agricultor justifica a entrada precoce dos animais na pastagem pelo incremento gerado no teor de proteína, mas isso interfere negativamente na produtividade da pastagem. No entanto, com a aplicação de nitrogênio, nota-se que não há diferença no teor de proteína quanto à época de pastejo, possibilitando a antecipação da entrada dos animais.

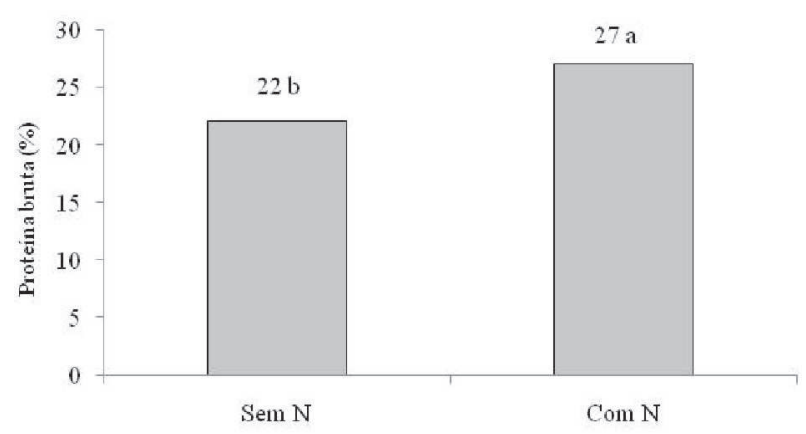

Figura 4. Teor de proteína bruta de pastos de aveia e azevém em função de diferentes doses de nitrogênio. Média de três épocas de corte. Sem N = sem nitrogênio; Com N = com $100 \mathrm{Kg}_{\text {de }} \mathrm{N} \mathrm{ha}^{-1}$.

\section{CONCLUSÕES}

A adubação nitrogenada proporciona expressivo incremento na produção de matéria seca de aveia e azevém, sendo possível antecipar a entrada dos animais em áreas de pastejo.

A adubação nitrogenada em aveia e azevém aumenta o teor de proteína bruta.

\section{REFERÊNCIAS}

Alvim MJ \& Moojen EL (1984) Efeitos de fontes e níveis de nitrogênio e práticas de manejo sobre a produção e qualidade da forragem de azevém anual. Revista Brasileira de Zootecnia, $13: 243-253$ 
Aquinaga AAQ, Carvalho PCF de, Anghinoni I, Pilau A, Aquinaga AJQ \& Gianluppi GF Dal (2008) Componentes morfológicos e produção de forragem de pastagem de aveia e azevém manejada em diferentes alturas. Revista Brasileira de Zootecnia, 37:15231530 .

Ben JR, Pottker D, Fontaneli RS \& Wiethölter S (1998) Resposta da aveia-preta à adubação nitrogenada em semeadura direta sobre pastagens nativas. Revista Brasileira de Ciência do Solo, $22: 723-730$

Cassol LC (2003) Relações solo-planta-animal num sistema de integração lavoura-pecuária em semeadura direta com calcário na superfície. Tese de Doutorado. Universidade Federal do Rio Grande do Sul, Porto Alegre. 143p.

Corsi M \& Nascimento Júnior D (1994) Princípios de fisiologia e morfologia de plantas forrageiras aplicados no manejo das pastagens. In: Peixoto AM, Moura, JC de, Faria VP da (Eds.) Pastagens: Fundamentos da Exploração Racional. Piracicaba. Fealq. p.15-47.

CQFS RS/SC (2004) Comissão de Química e Fertilidade do Solo. Manual de adubação e calagem para os Estados do Rio Grande do Sul e de Santa Catarina. Porto Alegre, RS: Sociedade Brasileira de Ciência do Solo. 400p.

Embrapa (1999) Centro Nacional de Pesquisa de Solos. Sistema Brasileiro de Classificação de Solos, Brasília. p.412.

Ferolla FS, Vasquez HM, Silva JFC Da, Viana AP, Domingues FN \& Aguiar RS da (2007) Produção de matéria seca, composição da massa de forragem e relação lâmina foliar/caule + bainha de aveia-preta e triticale nos sistemas de corte e de pastejo. Revista Brasileira de Zootecnia, 36:1512-1517.

Floss EL O (2001) Papel da aveia como componente de uma agricultura sustentável. $21^{a}$ Reunião da comissão brasileira de pesquisa de aveia, Lages. Anais, UDESC. p.11-22.

Hofer E \& Shikida PFA (2000) Estudo do custo de produção do leite na província de Santa Fé (Argentina) e no Estado do Paraná (Brasil). Revista Paranaense de Desenvolvimento, 98:99-107.

Lang CR (2004) Pastejo e nitrogênio afetando os atributos químicos do solo e rendimento de milho no sistema de integração lavoura-pecuária. Tese de Doutorado. Universidade Federal do Paraná, Curitiba. 89 p.
Lupatini GC, Restle J, Ceretta M, Moojen EL \& Bartz HR (1998) Avaliação da mistura de aveia preta e azevém sob pastejo submetida a níveis de nitrogênio. Pesquisa Agropecuária Brasileira, 33:1939-1943.

Matzembacher RG (2001) Ensaio com aveias brancas de duplo propósito na FUNDACEP In: $21^{\mathrm{a}}$ Reunião da comissão brasileira de pesquisa de aveia, Lages. Anais, UDESC. p.178-183.

Moreira FB, Cecato U, Prado IN Do, Wada FY, Rêgo FCA \& Nascimento WG (2001) Avaliação de aveia preta cv Iapar 61 submetida a níveis crescentes de nitrogênio em área proveniente de cultura de soja. Acta Scientiarum, 23:815-821.

Primavesi AC, Primavesi O, Chinelatto A \& Godoy R (2001) Indicadores de determinação de cortes de cultivares de aveia forrageira. Scientia Agricola, 58:79-89.

Reis RA, Rodrigues LR De, Coan O \& Resende KT de (1992) Efeito de diferentes épocas de colheita sobre a produção de forragem e de sementes de aveia preta. Pesquisa Agropecuária Brasileira, 27:111-117.

Richards JH (1993) Physiology of plants recovering from defoliation. In: 7th International Grassland Congress Palmerston North, New Zealand. Proceedings, New Zealand Grassland Association. p.85-93.

Rocha MG Da, Montagner DB, Santos DT dos, Freitas KF De, Pilau A \& Frizzo A (2004) Parâmetros produtivos de uma pastagem temperada submetida a alternativas de utilização. Revista Brasileira de Zootecnia, 33:1386-1395.

Rodrigues AA De \& Godoy R (2000) Efeito do pastejo restringido em aveia sobre a produção de leite. Pesquisa Agropecuária Brasileira, 35:551-556.

Soares AB \& Restle J (2002) Produção animal e qualidade de forragem de pastagem de triticale e azevém submetida a doses de adubação nitrogenada. Revista Brasileira de Zootecnia, 31:908917(suplemento).

Tedesco MJ, Gianello C, Bissani CA, Bohnen H \& Volkweiss SJ (1995) Análise de Solo, Plantas e Outros Materiais. 2a ed. Porto Alegre, Universidade Federal de Rio Grande do Sul. p.174. 